Note: This is the author post-print version of this article. The final version of this article was published as:

Karvonen, Andrew. 2013. Towards systemic domestic retrofit: a social practices approach, Building Research and Information 41(5): 563-574, doi 10.1080/09613218.2013.805298

http://www.tandfonline.com/doi/abs/10.1080/09613218.2013.805298

\title{
Towards systemic domestic retrofit: a social practices approach
}

\section{Andrew Karvonen}

\begin{abstract}
The current housing stock accounts will play an important role in achieving the 2050 national carbon reduction targets. Upgrading the energy performance of the existing housing stock is a significant challenge because retrofit activities are shaped by a wide range of fragmented policies, programmes, and actors. Existing approaches to housing retrofit focus on regulations, financial incentives, and information provision but it is argued these are insufficient to realise large-scale, deep changes in energy consumption. An agenda is proposed for systemic domestic retrofit to realise radical changes in the housing stock through community-based partnerships. These programmes are based on a social practices approach that promotes social innovation. Wide-ranging energy efficiency upgrades can be achieved through the development and realisation of customised solutions to local groups of houses through facilitated engagement between occupants, housing providers, community groups, local authorities, and construction professionals. Community-based domestic retrofit programmes serve to reframe the governance of domestic energy performance and suggest alternative routes for realising significant reductions in energy demand through changes in stakeholders' understanding and social practices (habits, perceptions and motivations) when coupled with physical interventions.
\end{abstract}

Keywords: energy efficiency, housing, retrofit, socio-technical, social practices, sustainable consumption 


\section{Introduction}

High carbon consumption is embedded in contemporary British lifestyles and this is clearly evident in the domestic building stock. Housing accounts for over a quarter of the UK's carbon emissions and will play a significant role in meeting the stringent carbon reduction targets of 2050. The energy performance of houses is 'locked in' during design and construction activities, and opportunities for upgrade only arise during infrequent refurbishment activities. ${ }^{1}$ Reflecting on domestic retrofit activities, a key conclusion was:

'empirical evidence and experience suggest that it will be neither particularly easy nor particularly cheap to reduce energy use in buildings. However, there is a perception in government that energy efficiency in buildings is straightforward and requires minimal investment.'

Oreszczyn and Lowe (2010: 110)

Challenges to energy efficient domestic retrofit include a highly variegated housing stock, a low rate of property turnover, disruption and inconvenience to occupants, undesirable payback periods for many energy efficiency strategies, lack of occupant interest in energy efficiency, and the lack of a knowledgeable and competent workforce to advise homeowners and implement energy efficiency strategies. Whereas a small number of actors (notably national homebuilders and developers) dominate the new-build housing agenda, the existing housing stock involves thousands of product manufacturers, installers, local councils, and charity organisations as well as building owners and occupants. As such, developing and realising a systemic domestic retrofit agenda is a significant challenge due to the balkanised character of the retrofit industry (Clarke, 2006; Oreszczyn and Lowe, 2010). Achieving the UK Government's 2050 carbon emissions reduction goals of 80\% (against a baseline of 1990 levels) will arguably require more than conventional tools of regulations, economic incentives, and information provision; instead, they will require multifaceted strategies that can leverage the diversity and complexity of the existing housing stock and the multiple individuals and institutions who act upon it.

The term 'retrofit' is used here to denote an upgrade to an existing house to meet contemporary norms and standards or to prepare for future conditions. Here, 'retrofit' is synonymous with renovation, modernization, restoration, and rehabilitation, and describes those activities undertaken in households that go beyond routine maintenance and repair activities (Meijer et al., 2009). Furthermore, the focus is limited to energy efficiency and carbon reduction; however it is also important to recognise that homeowners are also motivated to retrofit their houses to improve comfort, convenience, and aesthetics.

The aim of this article is to formulate an agenda for systemic domestic retrofit that can realise radical changes to the energy performance of the existing UK housing stock. The overarching argument is that existing approaches to housing retrofit are necessary but insufficient to realise large-scale changes in energy consumption. Achieving widespread upgrades to the UK housing stock will require new approaches that involve local, 
community-based programmes that simultaneously address the social and technical issues of domestic energy use.

The article is structured as follows. First, the evolution of the UK housing stock, and current prognoses for retrofit are summarised, along with the majority of activities which revolve around regulations and financial incentives, information dissemination and skills training, and demonstration projects that target individual occupants and building professionals. Then, the social practices approach is introduced and applied to community-based housing retrofit programmes. While these programmes vary in their methods and scope, they share a focus on targeting groups of houses and developing a community of interest around domestic retrofit. Further, they offer an alternative vision for transforming the housing stock by placing occupants at the centre of refurbishment activities. The targeted scale between the individual house and the national housing stock creates a context-specific approach to domestic energy efficiency. Finally, it is argued that community-based programmes can complement rather than replace existing strategies of domestic retrofit to create large-scale, deep changes to domestic energy consumption.

\section{Energy efficiency and the housing stock}

The current UK housing stock comprises more than 26 million dwelling units encompassing a wide range of ages and types (Utley and Shorrock, 2012) (Fig. 1). This is due to the evolution in the building industry from local homebuilders of the 1930s to regional diversification of the 1960s to national homebuilders in the last decades of the twentieth century (Goodier and Pan, 2010) as well as changes in technologies and materials used for domestic buildings (e.g., cavity walls, windows, insulation, central heating, and fuel sources). The median dwelling in the UK was built between 1939 and 1959, making the British housing stock amongst the oldest in Europe (Lowe, 2007). Energy performance can be generally correlated with building age, although individual domestic energy performance varies widely due to the frequency and types of refurbishment as well as wide-ranging occupancy patterns. Houses from the nineteenth and twentieth centuries were built with solid walls whilst most houses from the 1930s onward were built with cavity walls to prevent damp penetration (Roberts, 2008).

[Fig. 1 near here]

In the last four decades, domestic energy consumption in the UK has increased whilst carbon emissions have dropped significantly due to the decarbonisation of energy supply. In 1970 , solid fuels accounted for almost half of delivered energy whereas in 2001, natural gas and electricity accounted for $90 \%$ of delivered energy (Lowe, 2007). This shift in energy source resulted in lower costs, increased convenience and reliability, and reduced carbon emissions (Oreszczyn and Lowe, 2010). Further decarbonisation is expected to occur as natural gas and high-carbon forms of energy are replaced by renewable energy systems at the individual, district, and grid scales (Johnston et al., 2005). Looking towards 2050, it is 
understood that 'the decarbonization of the electricity system is a necessary condition for the decarbonization of the domestic sector' (Lowe, 2007: 422).

Beyond the supply side of domestic energy, building regulations have had a significant influence on reducing the energy demand for houses and thus, on domestic carbon emissions. Energy performance standards for houses in England and Wales were introduced in the Building Regulations in 1976 , with the most stringent performance requirements introduced since the late 1990s. This has resulted in carbon emissions in new dwellings that are 40 to $50 \%$ lower than the housing stock mean (Lowe, 2007). Heating systems and envelope components (lofts, walls, and windows) have been targeted for performance upgrades (SDC, 2006; Lowe, 2007; Utley and Shorrock, 2008; Stafford et al., 2011; Utley and Shorrock, 2012) and the aggregate effect of these energy performance measures has been significant. Utley and Shorrock (2008) calculated the SAP 2005 rating of the average dwelling within the housing stock from 1970 to 2006 (Fig. 2). ${ }^{2}$ The data show a continual increase in the SAP rating of the average dwelling from 18 to 52 due to energy efficiency improvements as well as the replacement of inefficient older properties with higher performance newbuild properties.

[Fig. 2 near here]

The energy consumption in the average British dwelling in 2001 was slightly lower than in 1974 , despite a large increase in the number of dwellings with central heating as well as increasing standards of comfort and additional appliances and household electronics (Shorrock et al., 2005). Likewise, the combination of fuel shifts and reductions in dwelling heat loss has reduced the carbon intensity of space heating by a factor of approximately four (Lowe, 2007). Fig. 3 illustrates carbon emissions from domestic energy consumption in the UK between 1970 and 2001, with a gradual trend of reduced carbon emissions over three decades. Oreszczyn and Lowe (2010) estimate that if this trend continues to 2050, the UK could reduce carbon emissions from domestic buildings by about $60 \%$ (compared to 1990 levels). However, it would take an additional 20 years or an increase in energy performance gains and decarbonisation of the energy supply to reach the $80 \%$ reduction in carbon emissions as proposed by Government (Committee on Climate Change, 2008). Thus, there is a need to look beyond the endogenous changes in domestic energy consumption and explore how these changes might be accelerated in the existing housing stock.

[Fig. 3 near here]

\section{The challenge of systemic retrofit}

General statistics on energy and carbon performance of the UK housing stock are readily available, but detailed data on domestic retrofit activities are scarce due to the fragmented nature of refurbishment activities. As Oreszcyzyn and Lowe (2010: 109) note, 'We are unable to disentangle the impact of post-construction improvements to older buildings.' In the future, it would be reasonable to assume that domestic retrofit projects will adopt the 
new-build industry's energy efficiency hierarchy: beginning with the building fabric ('fabric first') and then reducing energy loads in the building before providing low-carbon energy supply for the remaining energy demands. As Stafford et al. (2011: 8) remark, 'Primary gains will be achieved via improved fabric performance and this should be the initial focus of retrofit strategies.'

Beyond fabric strategies and the upgrade of heating systems and appliances, there are significant challenges with further energy efficiency interventions due to longer and less attractive payback periods (Shorrock et al., 2005). The Department of Energy and Climate Change's 2011 Carbon Plan calls for the 'low-hanging fruit' or 'easy wins' of energy efficiency to be completed by 2020 while subsequent decades will need to address the more challenging aspects of improving energy performance (DECC, 2011). Stafford et al. (2011) argue that while it is technically feasible to retrofit existing housing to a level of thermal performance close to that of low-carbon new-build houses, in some cases this will be prohibitively expensive and could approach the cost of demolition and rebuilding. Johnston et al. (2005) concur that achieving carbon savings above $80 \%$ will be technically demanding.

Meanwhile, the policy framework for improving the energy performance of existing housing is fragmented, with regulations, incentives, and programmes having a wide range of direct and indirect influences (Table 1). The Sustainable Development Committee (2006) calls for a national regulatory standard for the existing housing stock based on the BRE Ecohomes Existing Buildings standard while the Centre for Alternative Technologies (2010) calls for a 'Code for Sustainable High-Performance Refurbishment.' In both cases, the aim is to adopt a single regulation (similar to the Code for Sustainable Homes in new-build housing) to serve as a common guide for domestic energy retrofit. The regulation could be applied when houses are sold to new owners and through increasing energy efficiency standards for new building components. In July 2012, the Building Research Establishment launched the BREEAM Domestic Refurbishment Scheme, a design and assessment method to assist developers, designers, and consultants in domestic retrofit projects. Those projects that participate in the scheme can qualify for a rating from Pass to Outstanding based on a range of design and construction criteria including energy, water, materials, and so on (similar to other BREEAM schemes) (BRE, 2013).

[Table 1 near here]

Beyond the policies and regulations noted above, another approach to upgrading the domestic building stock involves the provision of information. The underpinning idea is that energy efficient upgrades of housing are stymied by stakeholders' lack of knowledge. Information hubs and training centres such as the Centre for Refurbishment Excellence in Stoke-on-Trent provide ready access to products, techniques, information, best practices, and case studies, as well as training courses to inform and upskill retrofit construction professionals and homeowners. Information is also provided through demonstration projects and programmes. An example of this is the Superhomes network, a database of 
more than 100 exemplary houses that have achieved at least a $60 \%$ reduction in carbon emissions. Open days and public tours are used to showcase exemplary retrofit projects in specific locales. The programme allows for retrofit knowledge and strategies to be demonstrated in the real world. The expectation is that homeowners will tour the houses, ask questions, and then use their newfound insights to inform the retrofit strategies in their own houses. Table 2 provides examples of information dissemination resources, programmes, and projects for domestic retrofit.

[Table 2 near here]

Voluntary standards, incentive programmes, information provision, and demonstration projects are effective strategies to assist individuals who are committed and enthusiastic about reducing their energy use but it is unlikely that these measures will lead to a radical reduction in carbon emissions from the domestic building stock (SDC, 2006). ${ }^{3}$ As Vergragt and Brown (2012: 412-3) remark, 'All formal standards, by being a product of widely based consultation - either through professional networks or the political process of rule-making are rarely reaching out for radical change.' Advocates of these approaches tend to adhere to a 'rational choice' model that encourages individuals to reduce their energy consumption by appealing to their desire to realise economic savings, to improve their health, and/or to protect the environment. This perspective has been criticised by scholars of sustainable consumption for its individualist perspective (Hobson, 2002; Gram-Hanssen, 2009, 2010; Shove, 2010; Spaargaren, 2011; McMeekin and Southerton, 2012). Two examples from the literature state:

'Information can be an important first step in prompting people to change their behaviour. However, information alone is unlikely to motivate changes as a matter of course.'

Moloney et al. (2010: 7616)

'... market mechanisms, easy retrofits and economic rationalist understandings of human actions are unlikely to achieve widespread systemic changes needed to address the environmental and social challenges of climate change, largely because they do not challenge the status quo and overlook the routines of everyday life.'

Maller et al. (2012: 257)

The rational choice perspective fails to acknowledge the housing stock as 'a cultural asset that is embedded in the fabric of everyday lifestyles, communities, and livelihoods' (Ravetz, 2008: 4463). Occupants are actively involved in shaping energy profiles and are at the centre of a complex network of activities, organisations, and systems that produce domestic carbon emissions while their role in the realisation of long-term carbon emission reductions is often underappreciated or unacknowledged. The rational choice perspective does not take into account the different ways that occupants inhabit their houses, how they perceive their resource consumption activities, and how and why they decide to retrofit their houses. 
From a homeowner perspective, there are multiple reasons for the slow uptake of energy efficiency measures: capital costs and the uncertainty of final costs; the risk of downstream teething problems; potential impacts on aesthetics and property value; and inconvenience and disruption during retrofit activities (SDC, 2006; UKGBC, 2008; Lomas, 2009; Bartiaux et al., 2011; Vergragt and Brown, 2012). Homeowners often decide to renovate their houses to modernise kitchens and bathrooms, and while they are interested in improved comfort conditions, energy performance tends to be a lower priority (Bell and Lowe, 2000; Meijer et al., 2009). In effect, there is a mismatch between current policy and information offerings for domestic retrofit and the lived reality of how houses are inhabited and how they change over time.

\section{Applying the social practices approach to domestic retrofit}

Developing a systematic domestic retrofit agenda in the UK can benefit from thinking beyond the technical and economic aspects of domestic energy use. Reflecting on the social aspects of domestic energy consumption, Lomas (2010: 7) asks how a strategic retrofit agenda might tap into the 'lifestyle benefits' that are important to homeowners and occupants: 'Are there some lifestyle benefits that could be attached to the worthy but dull energy-reduction technologies?' A crosscutting perspective from sociology, political science, and geography called 'social practices theory' goes further by emphasising the complex relations between consumers, producers, and systems of provision (Spaargaren and van Vliet, 2000; Reckwitz, 2002; Southerton et al., 2004; Warde, 2005; Shove and Walker, 2010). Inspired by the work of Giddens $(1984)$, Bourdieu $(1977,1990)$ and other social theorists, the aim of social practices theory is to overcome the structure-actor dualism that pervades contemporary society. Practices are shaped not only by systems of provision (e.g., infrastructures and supply chains) but also by lifestyles (e.g., everyday habits and personal choices). Social practices theory emphasises the interdependent relationship between the two (Spaargaren and van Vliet, 2000; Darton et al., 2011). Social practices are a combination of materials (objects, hard infrastructure), competences (skills and know-how), and images (meanings, ideas and interpretations) that shape resource consumption (Shove and Pantzar, 2005; Darton et al., 2011). The social practices approach is arguably useful because it bridges individual lifestyles and broader socio-technical systems of provision (Spaargaren and van Vliet 2000; Hargreaves, 2011). ${ }^{4}$

Several studies have used the social practices approach to examine domestic DIY activities undertaken by occupants with a focus on the dynamic use of tools, materials, and labour (Watson and Shove, 2005; Hand et al., 2007; Bartiaux et al., 2011; Maller and Horne, 2011; Maller et al., 2012). These studies extend beyond the household to include systems of provision (e.g., energy systems) as well as networks of professionals and regulators who influence domestic living. It has been noted that:

'renovation is a 'whole household' affair, and involves formal and informal relations to be built and tested, within and beyond the immediate home and household.

Relationships with building professionals require the knowledge and skill to navigate a 
complex system of provision to access materials, products and technologies.'

Maller et al. (2012: 263)

A limitation of these studies is that they continue to focus on domestic activity at the micro scale. The material and social contexts revolve around the individual homeowner and the individual home. Another limitation is that domestic retrofit work is often periodic and inconsistent rather than an everyday occurrence:

'Renovations are often not based on habitual or routinized doings and sayings as people e.g. only replace windows a few times in their lifetime.'

Bartiaux et al (2011: 70)

This reflects a broader critique of the social practices approach in that the emphasis on the everyday makes it difficult to envision how larger changes might be realised (Geels, 2010; Birtchnell, 2012). Reflecting on the spatial and temporal scale issues of the practices approach, Watson (2012: 489) cautions that the 'microfocus of practice research, while foundational, risks missing the radical implications and potential of the concept.'

One response to this critique is to examine 'bundles', 'systems', or 'chains' of practices rather than individual practices (Urry, 2004; Warde, 2005; Spaargaren, 2011; Watson, 2012). With respect to domestic retrofit, this means not simply looking at the practice of maintaining thermal comfort in one's house or the practice of DIY but rather interrogating the multiple practices that 'hang together' in the long-term habitation of a house: thermal comfort, cooking, cleaning, sleeping, entertaining, and so on. It has been argued that the:

'transition to low carbon communities requires an understanding of community practices and resultant emissions, as well as the technologies, infrastructures and institutions associated with and accessed by communities Moreover, it requires an understanding of the connections between these integrated system components, their dynamics, a clearly defined transition pathway and potential "levers" to catalyse "transitioning"".

Moloney et al. (2010: 7614)

Such a perspective resonates with the governance of social practices (Shove and Walker, 2010; Spaargaren, 2011) as well as recent work on 'grassroots innovations' (Seyfang and Smith, 2007; Seyfang, 2009; Seyfang et al., 2010; Seyfang and Haxeltine, 2012; Smith, 2012).

To address the temporal aspects of domestic retrofit, it is also necessary to shift the social practices approach away from everyday routines and habits to account for domestic activities that span month, years, or even decades. Warde (2005: 139) argues that practices 'have a trajectory or path of development' that are constantly being reproduced as people lead their daily lives. This trajectory can be disrupted and modified during significant 'moments of change' such as leaving home for the first time, transitioning to parenthood, 
moving house, and moving into retirement, as well as exogenous events such as the 1970s oil crisis or the 2008-9 'credit crunch' (Thompson et al., 2011). Domestic retrofit activities can be understood as one of these significant 'moments of change' when the occupants' activities and perceptions can shift dramatically. There is emerging evidence that targeting these 'moments of change' (Darnton et al., 2011) or 'trigger points' (EST, 2011) is an effective way to realise more sustainable patterns of consumption. They serve as windows of opportunity to reconfigure the dynamic and complex relations between inhabitants and the built environment.

More broadly, the focus on the temporal aspects of domestic retrofit recognises that the housing stock is dynamic. Domestic retrofit is not an activity of changing a house from one steady state to another - from poor energy performance to exceptional energy performance - but an intervention into the rhythms of domestic habitation. This suggests that retrofit is not simply a one-off intervention but can be linked to regular activities of maintenance and repair (Brand, 1994; Graham and Thrift, 2007; Lomas, 2009; Hodson and Marvin, 2011; Fawcett, forthcoming). Meijer et al. (2009: 545) write, 'Natural renovation moments that provide a cost-effective opportunity to replace components with more efficient ones [include] relocation, replacement renovation of defective components, and such modernization activities as changing kitchens and bathrooms.' This suggests that there are both major and minor 'moments of change' that can be leveraged for energy performance upgrades. For example, energy efficiency measures can be gradually introduced as various subsystems of houses are replaced (e.g., 10 years for heating systems, 20 years for windows, and 50 years for roofs) or when houses undergo major refurbishment every 20 to 30 years (SDC, 2006; Lowe, 2007; Ravetz, 2008). Of course, a significant challenge of tapping into the rhythms of repair and maintenance is to plan for the long-term so an early intervention does not negate or create problems for later upgrades.

The social practices approach is particularly useful in recognising that retrofit is neither simple nor can it be solved with a 'one-size-fits-all' approach due to the physical diversity of the housing stock, the gap between modelled and actual performance, the introduction of new and improved building products, the fragmentation of the retrofit workforce, and the activities and opinions of occupants:

'we are trying to change a very complex system, with lots of moving parts. And it is not easily reduced to simple explanations (e.g., 'it's technology not people' or 'people are selfish') or simply policy approaches (e.g., 'just get the prices right' or 'it's just that financial incentives are needed).'

Lutzenhiser (2008: 3, quoted in Stephenson et al., 2010: 6121)

The complexity of the retrofit problem means that: 'solutions need to be specifically tailored to the building or group of buildings in question' (Stafford et al., 2011: 12-13). The next section describes such customised solutions to domestic retrofit that follow a communitybased social practice approach. 


\section{Local and regional retrofit initiatives}

A growing number of local and regional programmes in the UK take a more holistic approach to domestic retrofit. These programmes target specific properties and undertake upgrades to reconfigure dwelling practices (EST, 2009). They go further than supplying information and providing incentives by emphasizing the importance of recursive learning processes to facilitate the coevolution of the built environment and society (see Brand, 1994; Brand, 2005; Moore and Karvonen, 2008; Oreszczyn and Lowe, 2010; Ross, 2011; Stafford et al., 2011; Vergragt and Brown, 2012). Stafford et al. (2011: 7) call for a 'system of continual feedback' that will allow the building community to 'learn as we go.' Likewise, Oreszczyn and Lowe (2010) argue for a move away from the natural science model of building scientists and towards an approach where research activities and knowledge transfer are more closely linked. Vergragt and Brown (2012) describe learning processes where homeowners and occupants are active participants in the retrofit processes rather than passive targets. There is a shared understanding that reconfiguring socio-technical systems on a broad scale will require participation of occupants and homeowners to afford empowerment, ownership, and collective control (Maloney et al., 2010).

An example of the grounded, iterative learning approach to domestic retrofit is Refit West, a consortium of environmental groups, architects, and builders who partner to assist homeowners in improving the energy performance of their houses (Ross, 2011; Refit West, 2013). The programme involved the retrofitting of ten houses in Bristol and the west of England and placed the homeowner at the centre of the retrofit process. The project team provided information and options for the homeowner to consider and then assisted in the development of customised solutions and the commissioning of the retrofit activities. They argue that:

'a flexible and people-centred approach, delivering a positive experience for early adopters, is the best way to radically transform our property market and housing stock.'

(Ross, 2011: 5)

To complete multiple domestic retrofits successfully, they convened an expert panel to identify the barriers that were relevant to the locality. Then they worked to build the homeowners' trust in the mutually agreed retrofit strategy and assisted in selecting the contractors to complete the work. These activities coalesced into a community of interest around energy retrofit wherein owners and occupants shared their experiences and insights.

A larger example of domestic innovation through learning is Warm Zones, a not-for-profit subsidiary of National Energy Action (Warm Zones, 2013). A Warm Zone is a local or regional partnership that includes the local authority, energy suppliers, housing companies, and other organisations from various sectors to coordinate and target domestic energy 
efficiency strategies. The programme began with five pilot areas in 2001 and currently has 13 Warm Zones that have delivered an estimated $£ 32$ million in energy efficiency measures to 320,000 houses. The partnership facilitates the strategic local delivery of domestic retrofit interventions to simultaneously address fuel poverty and support the local economy of building trades. As the Warm Zones website states:

'By improving domestic energy efficiency, increasing incomes and tackling fuel poverty, each Warm Zone makes a major contribution in boosting the local economy, improving the health and wellbeing of residents \& tackling climate change!'

(Warm Zones, 2013)

The above examples are two amongst dozens of programmes and initiatives in the UK that rely on locally-based, learning-by-doing retrofit interventions that customise energy performance interventions for each and every house (Table 3). Whereas the majority of energy-efficiency programmes emphasise the rollout of new technologies and the promise of financial incentives, here the focus is on harmonising changes with the already existing socio-technical system (Vergragt and Brown, 2012). Information provision and incentive programmes are an important part of these programmes but they are complemented by surveys, consultations with homeowners and occupants, cost estimates and energy models, coordination of building work, feedback with the occupants after the work is completed, and long-term monitoring. They are often characterised as 'experiments' or 'pilot studies' to highlight the tentative, open-ended, and exploratory character of the programmes while also emphasising the importance of learning and feedback. At the same time, the stakeholders are eager to replicate and expand the programmes to get more retrofit stakeholders involved.

These community-based programmes resonate with the social practices approach by embracing the socio-technical complexity of domestic retrofit. They do not prescribe a specific technology or appeal to the economic rationality of homeowners but work to reconfigure the chains of practices that coalesce in the consumption of domestic energy. The initial intervention creates a 'window of opportunity' in which homeowners can participate in a dialogue of learning and doing, retrofitting their own house while reflecting on the experiences of others. In the longer term, there is potential for these communitybased retrofit programmes to sustain a community of interest around energy efficiency and sustainable living.

[Table 3 near here]

Central to the success of these programmes are intermediaries who can bring building science, economics, and policy knowledge to bear on the retrofit decisions of homeowners (Brand and Karvonen, 2007; Karvonen and Brand, 2009; Guy et al., 2011). These intermediaries bridge the gap between distant Government carbon reduction targets and 
the rhythms of domestic life by developing trust and confidence in the tools, processes, and actors involved in domestic retrofit (Ross, 2011; Vergragt and Brown, 2012). ${ }^{5}$ This is perhaps the most crucial element of these programmes as the intermediaries provide the energy and coordination to make these programmes a success. Another crucial component to these programmes is their ability to persist over time rather than provide a brief flurry of retrofit activity and then fade away. To make deep and long-term changes in the energy performance of housing, there is the need to develop a culture of energy (Stephenson et al., 2010). These programmes can provide the seeds for such a culture but it remains to be seen as to whether they can flourish and be self-sustaining in the long term.

\section{Conclusions}

There have been significant improvements in domestic building energy performance in the UK, particularly over the last four decades, due to the decarbonisation of energy supplies, increasingly stringent Building Regulations, and the introduction of more efficient housing technologies and techniques. But given the UK's aggressive 2050 carbon reduction targets, there is a pressing need for systemic approaches to upgrade the energy performance of the existing housing stock:

'retrofitting of existing buildings for improved energy performance will play a vital role in achieving the UK's carbon reduction targets, but the problem is complex and the route to optimum effectiveness is not yet clear.'

Stafford et al. (2011: 25)

The conventional approaches of regulation, economic incentives, information provision, and demonstration are necessary but insufficient in realising systemic domestic energy performance improvements. Instead, there is a need to develop a broader approach to domestic retrofit that simultaneously addresses the systems of provision as well as occupant habits, perceptions, and motivations. The social practices approach uses a sociotechnical perspective that recognises homeowners and occupants as embedded in a complex socio-technical landscape:

'identifying the dimensions of the socio-technical system of the housing stock reveals the interdependencies between its elements and the drags on the system.'

Vergragt and Brown (2012: 414)

Making widespread changes to these complex systems involves multifaceted negotiations and customised interventions at the community scale. Others have argued that:

[Community-based programmes] are more likely to address the more challenging social, institutional and technical barriers and constraints. [They] also have the advantage of identifying locally specific barriers whether they are systemic, for example, local regulations and infrastructure provision, or behavioural by exploring and challenging variations in social practices within their communities and as a result 
work with those communities to identify and tailor different approaches to addressing them.

Moloney et al (2010: 7621)

Community-based programmes of domestic retrofit complement conventional energy efficiency approaches of regulations, incentive programmes, and information provision while suggesting new forms of intervention that are experimental, flexible, and customised to particular locales (Karvonen, 2011). The examples summarised above provide clear evidence that these strategies of joined-up learning and doing can have wide-ranging and significant influence on domestic energy performance. These programmes rely on social rather than technical innovation to realise substantial changes in the housing stock (Seyfang and Haxeltine, 2012; Vergragt and Brown, 2012). While they render policy responses less straightforward and depend upon intermediary organisations and individuals to sustain them in the long term, community-based programmes of domestic retrofit hold significant promise for realising systemic change in the UK housing stock.

\section{References}

Bartiaux, F., Gram-Hanssen, K., Fonseca, P., Ozolina, L., and Christensen, T.H. (2011) A practice-theory based analysis of energy renovations in four European countries. Paper presented at the ECEEE 2011 Summer Study - Energy Efficiency First: The Foundation of a Low-Carbon Society.

Bell, M., and Lowe, R. (2000) Energy efficient modernisation of housing: a UK case study. Energy and Buildings, 32, 267-280.

Birtchnell, T. (2012) Elites, elements and events: practice theory and scale. Journal of Transport Geography, 24, 497-502.

Bourdieu, P. (1977) Outline of a Theory of Practice, Cambridge University Press, Cambridge. Bourdieu, P. (1990) The Logic of Practice, Polity Press, Cambridge.

Brand, R. (2005) Synchronizing Science and Technology with Human Behaviour, Earthscan: London.

Brand, R., and Karvonen, A. (2007) The Ecosystem of Expertise: Complimentary Knowledges for Sustainable Development. Sustainability: Science, Practice, and Policy, 3(1), 21-31.

Brand, S. (1994) How Buildings Learn: What Happens after They're Built, Penguin: New York. Building Research Establishment (BRE) (2013) BREEAM Domestic Refurbishment Scheme website, http://www.breeam.org/page.jsp?id=228 (last accessed 3 February 2013).

CALEBRE (2013) CALEBRE website, http://www.calebre.org.uk/ (last access 3 February 2013).

Centre for Alternative Technologies (2010) Zero Carbon Britain 2030: A New Energy Strategy, CAT Publications, Machynlleth.

Clarke, L. (2006) Valuing labour. Building Research and Information 34(3), 246-256.

Committee on Climate Change (2008) Building a Low-Carbon Economy - The UK's Contribution to Tackling Climate Change, The Stationery Office, London.

Crosbie, T. and Baker, K. (2010) Energy-efficiency interventions in housing: learning from the inhabitants. Building Research \& Information, 38(1): 70-79. 
Darnton, A., Verplanken, B., White, P., and Whitmarsh, L. (2011) Habits, Routines and Sustainable Lifestyles: A Summary Report To the Department for Environment, Food and Rural Affairs, AD Research and Analysis for Defra, London.

Department for Communities and Local Government (DCLG) (2006) Review of Sustainability of Existing Buildings, DCLG Publications, London.

Department for Communities and Local Government (DCLG) (2011) English Housing Survey: Housing Stock Summary Statistics 2009, DCLG Publications, London.

Department of Energy and Climate Change (DECC) (2011) The Carbon Plan: Delivering Our Low Carbon Future, Department of Energy and Climate Change, London.

Department of Energy and Climate Change (DECC) (2012) Department of Energy and Climate Change website, http://www.decc.gov.uk (last accessed 21 January 2012).

Directgov (2012) Directgov website, http://www.direct.gov.uk (last accessed 21 January 2012).

Druckman, A., Chitnis, M., Sorrell, S., and Jackson, T. (2011) Missing carbon reductions? exploring rebound and backfire effects in UK households. Energy Policy 39: 3572-3581.

Energy Saving Trust (EST) (2009) Area Based Approach: Best Practice Guide, November 2009, Energy Saving Trust, London.

Energy Saving Trust (EST) (2011) Trigger Points: A Convenient Truth, February 2011, Energy Saving Trust, London.

Energy Saving Trust (EST) (2012) Energy Saving Trust website, http://www.energysavingtrust.org.uk (last accessed 21 January 2012).

Fawcett, T. (2002) Creative destruction? The role of increased demolition in creating a more sustainable UK housing stock. Proceedings of the 5th Symposium of the International Urban Planning and Environmental Association, Oxford, UK, 23-26 September 2002.

Fawcett, T. (forthcoming) Exploring the time dimension of low carbon retrofit. Building Research \& Information.

Geels, F.W. (2010) Ontologies, socio-technical transitions (to sustainability), and the multilevel perspective. Research Policy 31, 495-510.

Gentoo Group (2013) Gentoo Group website, Http://www.gentoogroup.com (last accessed 3 February 2013).

Giddens, A. (1984) The Constitution of Society: Outline of a Theory of Structuration, Polity Press, Cambridge.

Goodier, C., and Pan, W. (2010) The Future of UK Housebuilding, RICS HQ, London.

Graham, S., and Thrift, N. (2007) Out of order: understanding repair and maintenance. Theory, Culture \& Society, 24(3), 1-25.

Gram-Hanssen, K. (2009) Standby consumption in households analyzed with a practice theory approach. Journal of Industrial Ecology, 14(1), 150-165.

Gram-Hanssen, K. (2010) Residential heat comfort practices: understanding users. Building Research and Information, 38(2), 175-186.

Guy. S., Marvin, S., Medd, W., and Moss, T. (eds) (2011) Shaping Urban Infrastructures: Intermediaries and the Governance of Socio-technical Networks, Earthscan, London.

Hand, M., Shove, E., and Southerton, D. (2007) Home extensions in the United Kingdom: space, time, and practice. Environment and Planning D: Society and Space, 25, 668-681.

Hargreaves, T. (2011) Practice-ing behaviour change: applying social practice theory to proenvironmental behaviour change. Journal of Consumer Culture, 11(1), 79-99. 
Hertin, J., Berkhout, F., Gann, D.M., and Barlow, J. (2003) Climate change and the UK house building sector: perceptions, impacts and adaptive capacity. Building Research and Information, 31(3-4), 278-290.

Hobson, K. (2002) Competing discourses of sustainable consumption: does the 'rationalisation of lifestyles' make sense?. Environmental Politics, 11(2): 95-120.

Hodson, M., and Marvin, S. (2011) Urban retrofit - from project by project to systemic change. Town and Country Planning, 79(10), 429-433.

Johnston, D., Lowe, R., and Bell, M. (2005) An exploration of the technical feasibility of achieving $\mathrm{CO} 2$ emission reductions in excess of $60 \%$ within the UK housing stock by the year 2050. Energy Policy, 33, 1643-1659.

Karvonen, A. (2011) Politics of Urban Runoff: Nature, Technology, and the Sustainable City. London: MIT Press.

Karvonen, A., and Brand, R. (2009) Technical Expertise, Sustainability, and the Politics of Specialized Knowledge. In G. Kütting \& R.D. Lipshutz (Eds.), Environmental Governance: Power and Knowledge in a Local-Global World (pp. 38-59). New York: Routledge.

Lomas, K.J. (2009) Decarbonizing national housing stocks: strategies, barriers and measurement, Building Research and Information, 37(2), 187-191.

Lomas, K.J. (2010) Carbon reduction in existing buildings: a transdisciplinary approach, Building Research and Information, 38(1), 1-11.

Lowe, R. (2007) Technical options and strategies for decarbonizing UK housing. Building Research and Information, 35(4), 412-425.

Lutzenhiser, L. (2008) Setting the stage: why behaviour is important. Proceedings of the Behaviour, Energy and Climate Change Conference, 7-9 November 2007, Sacramento, CA.

Maller, C.J., and Horne, R.E. (2011) Living lightly: how does climate change feature in residential home improvements and what are the implications for policy? Urban Policy and Research, 29(1), 59-72.

Maller, C.J., Horne, R.E., and Dalton, T. (2012) Green renovations: intersections of daily routines, housing aspirations and narratives of environmental sustainability. Housing, Theory and Society, 29(3), 255-275.

McMeekin, A., and Southerton, D. (2012) Sustainability transitions and final consumption: practices and socio-technical systems. Technology Analysis \& Strategic Management, 24(4), 345-361.

Meijer, F., Itard, L., and Sunikka-Blank, M. (2009) Comparing European residential building stocks: performance, renovation and policy opportunities. Building Research and Information, 37(5-6), 533-551.

Moloney, S., Horne, R.E., and Fien, J. (2010) Transitioning to low carbon communities - from behaviour change to systemic change: lessons from Australia. Energy Policy, 38, 76147623.

Moore, S.A., and Karvonen, A. (2008) Sustainable architecture in context: STS and design thinking. Science Studies, 21(1), 29-46.

National Refurbishment Centre (NRC) (2012) National Refurbishment Centre website, http://www.rethinkingrefurbishment.com (last accessed 21 January 2012).

Oreszczyn, T., and Lowe, R. (2010) Challenges for energy and buildings research: objectives, methods and funding mechanisms. Building Research and Information, 38(1), 107-122.

Ravetz, J. (2008) State of the stock - what do we know about existing buildings and their future prospects?. Energy Policy, 36, 4462-4470. 
Reckwitz, A. (2002) Toward a theory of social practices: a development in culturalist theorizing. European Journal of Social Theory, 5, 243-63.

Refit West (2013) Refit West website, http://www.refitwest.com (last accessed 3 February 2013).

Roberts, S. (2008) Altering existing buildings in the UK, Energy Policy, 36, 4482-4486.

Ross, B. (2011) Refit West: Update from the Front Line, Forum for the Future, London.

Seyfang, G. and Smith, A. (2007) Grassroots innovations for sustainable development: towards a new research and policy agenda. Environmental Politics 16, 584-603.

Seyfang, G. (2009) The New Economics of Sustainable Consumption: Seeds of Change, Palgrave Macmillan, Basingstoke.

Seyfang, G., and Haxeltine, A. (2012) Growing grassroots innovations: exploring the role of community-based initiatives in governing sustainable energy transitions. Environment and Planing C: Government and Policy, 30, 381-400.

Seyfang, G., Haxeltine, A., Hargreaves, T., and Longhurst, N. (2010) Energy and communities in transition: towards a new research agenda on agency and civil society in sustainability transitions. WPEDM 2010-13, Centre for Social and Economic Research on the Global Environment, Norwich.

Shorrock, L.D., Henderson, J., and Utley, J.I. (2005) Reducing Carbon Emissions from the UK Housing Stock, BRE, Watford.

Shorrock, L.D., and Utley, J.I. (2003) Domestic Energy Fact File 2003, BRE Housing Centre, Watford.

Shove, E. (2010) Beyond the ABC: climate change policy and theories of social change. Environment and Planning A, 42, 1272-1285.

Shove, E., and Pantzar, M. (2005) Consumers, producers, and practices: understanding the invention and reinvention of Nordic walking. Journal of Consumer Culture, 5, 43-64.

Shove, E., and Walker, G. (2010) Governing transitions in the sustainability of everyday life. Research Policy, 39, 471-476.

Smith, A. (2012) Civil society in sustainable energy transitions, in G. Verbong and D. Loorbach (eds) Governing the Energy Transition: Reality, Illusion, or Necessity (Routledge, London), pp. 180-202.

Southerton, D., Chappells, H., and van Vliet, B. (eds) (2004) Sustainable Consumption: The Implications of Changing Infrastructures of Provision, Edward Elgar, Cheltenham.

Spaargaren, G. (2011) Theories of practices: agency, technology, and culture. Exploring the relevance of practice theories for the governance of sustainable consumption practices in the new world-order. Global Environmental Change, 21, 813-822.

Spaargaren, G., and van Vliet, B. (2000) Lifestyle, consumption and the environment: the ecological modernisation of domestic consumption. Society and Natural Resources, 9, 5076.

Stafford, A., Gorse, C., and Shao, L. (2011) The Retrofit Challenge: Delivering Low Carbon Buildings, Centre for Low Carbon Futures, York.

Stephenson, J., Barton, B., Carrington, G., Groth, D., Lawson, R., and Thorsnes, P. (2010) Energy cultures: a framework for understanding energy behaviours. Energy Policy, 38, 6120-6129.

Sustainable Development Commission (SDC) (2006) Stock Take: Delivering Improvements in Existing Housing, Sustainable Development Commission, London. 
Thompson, S., Michaelson, J., Abdallah, S., Johnson, V., Morris, D., Riley, K., and Simms, A. (2011) 'Moments of change' as Opportunities for Influencing Behaviour: A Report to the Department for Environment, Food and Rural Affairs, Defra, London.

Transition Streets (2013) Transition Streets website, http://www.transitionstreets.org.uk (last accessed 3 February 2013).

UK Green Building Council (UKGBC) (2008) Low Carbon Existing Homes. UK Green Building Council, London.

Unruh, G.C. (2000) Understanding carbon lock-in. Energy Policy, 28, 817-830.

Unruh, G.C. (2002) Escaping carbon lock-in. Energy Policy, 30, 317-325.

Urry, J. (2004) The 'system' of automobility. Theory, Culture and Society, 21(4-5), 25-39.

Utley, J.I., and Shorrock, L.D. (2008) Domestic Energy Fact File 2008, Department of Energy and Climate Change, London.

Utley, J., and Shorrock, L. (2012) Ninety Years of Housing, 1921-2011: Trends Relating to Living Standards, Energy Use and Carbon Emissions, FB 46, IHS BRE Press, Watford.

Vergragt, P.J., and Brown, H.S. (2012) The challenge of energy retrofitting the residential housing stock: grassroots innovations and socio-technical system change in Worcester, MA. Technology Analysis \& Strategic Management, 24(4), 407-420.

Warde, A. (2005) Consumption and theories of practice. Journal of Consumer Culture, 5(2), 131-153.

Warm Zones (2013) Warm Zones website, http://warmzones.co.uk (last accessed 3 February 2013).

Watson, M. (2012) How theories of practice can inform transition to a decarbonised transport system. Journal of Transport Geography, 24, 488-496.

Watson, M., and Shove, E. (2005) Doing it yourself? products, competence and meaning in the practices of DIY. Paper presented at the ESA 2005 Torun.

\section{Endnotes}

1. On the notion of 'carbon lock-in', see Unruh, 2000 and 2002.

2. SAP or Standard Assessment Procedure is a calculation methodology that generates a number used as an energy performance rating, with zero being extremely inefficient and 100 being self-sufficient.

3. Oreszczyn and Lowe (2010) call for a more radical approach to reducing the carbon footprint of domestic buildings via the development of a 'Manhattan Project' of retrofit, a national action plan involving a collaborative interdisciplinary group of well-funded and influential housing industry stakeholders that can fundamentally transform the housing stock through massive and widespread renovation. Such a national endeavour is an enticing recipe to realise a low-carbon British future, but it is difficult to imagine how the political will and financing could be mustered unless motivated by a catastrophic event of epic proportions such as a severe disruption in energy supplies or a significant increase in energy costs.

4. Social practices are most commonly referred to as a 'theory' but throughout this article, they are referred to as an 'approach' or a 'perspective' to acknowledge the tentative and dynamic character of this body of academic work. 
Figures

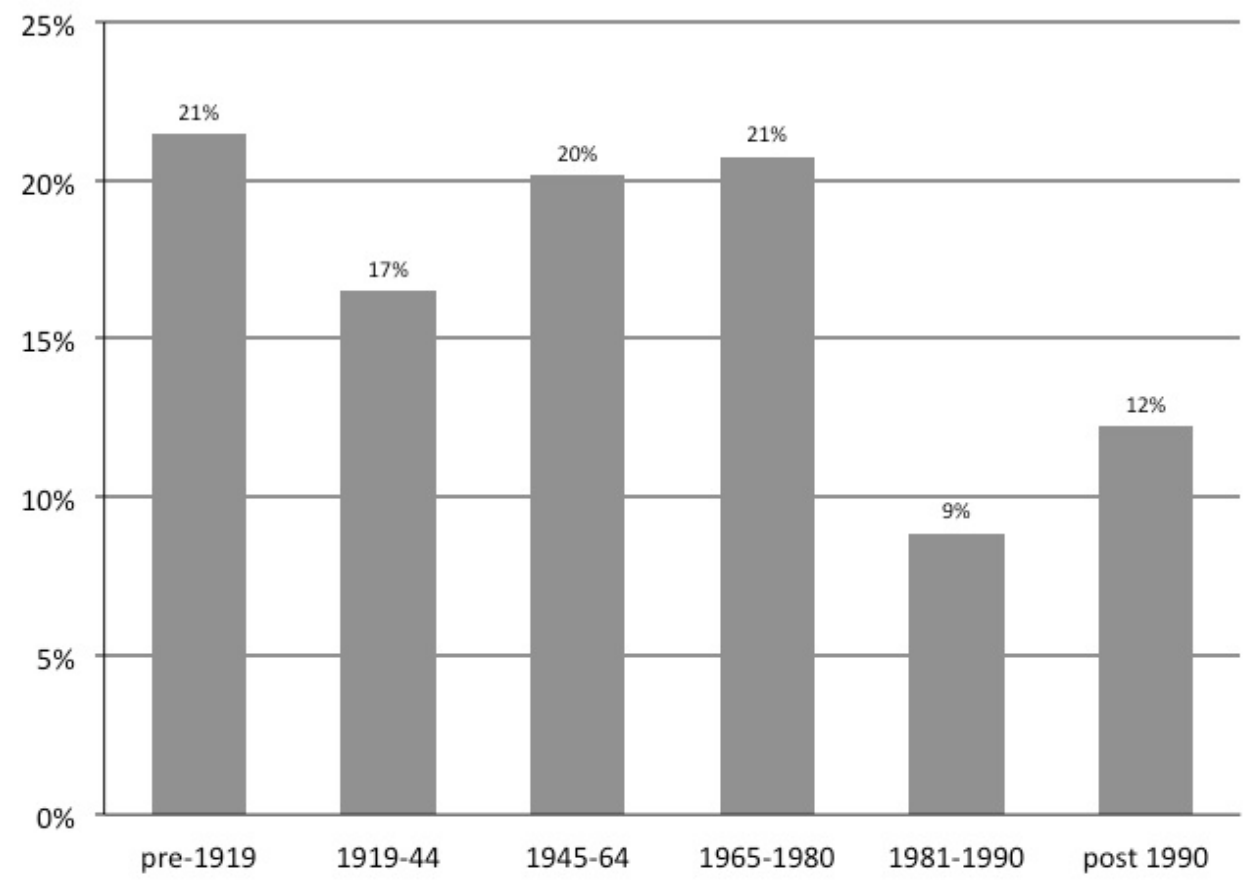

Fig 1 Age distribution of UK housing stock (Source: DCLG, 2011)

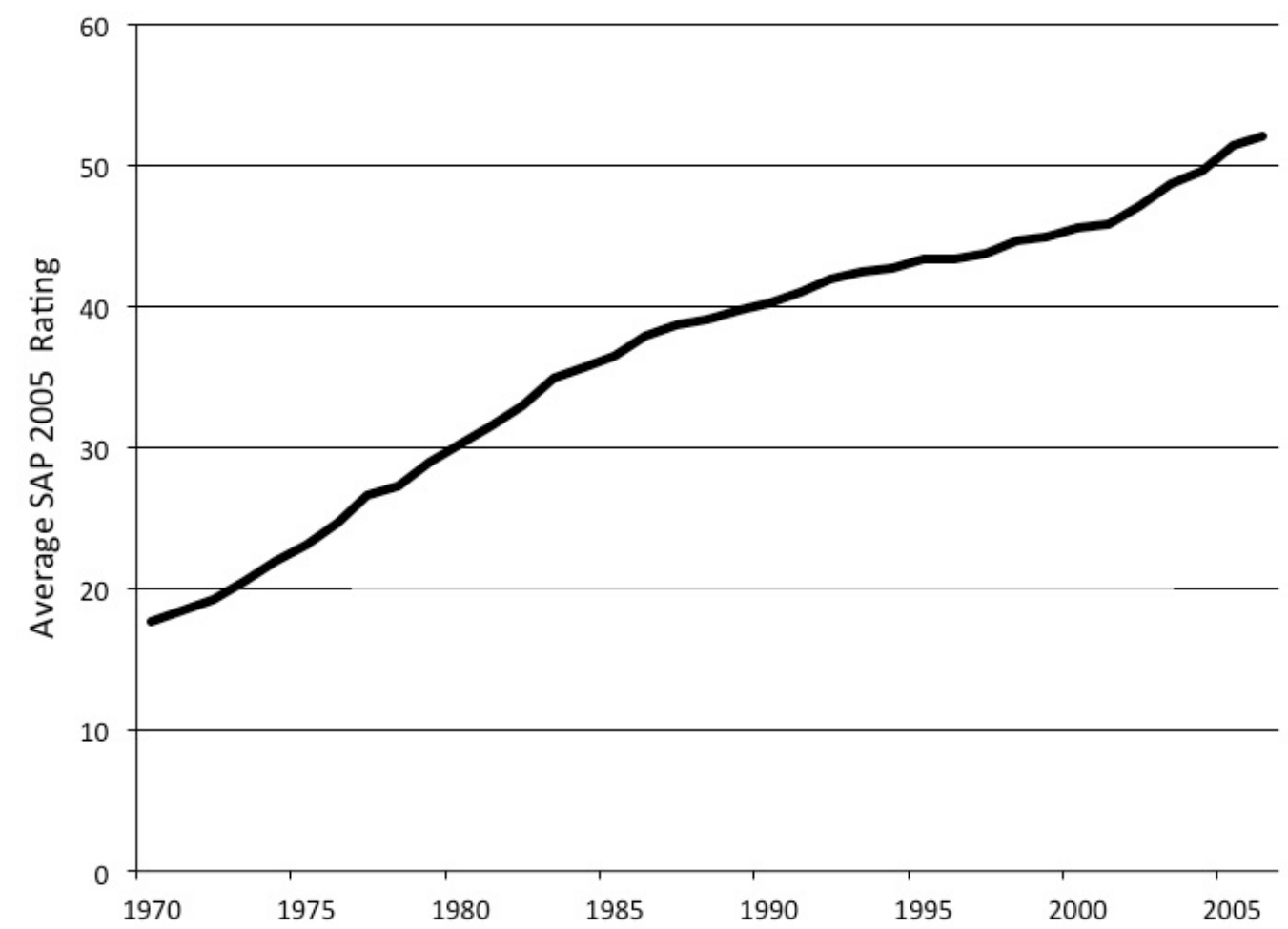

Fig 2 Average SAP 2005 rating of the UK housing stock, 1970 to 2006 (Source: Utley and Shorrock, 2008) 


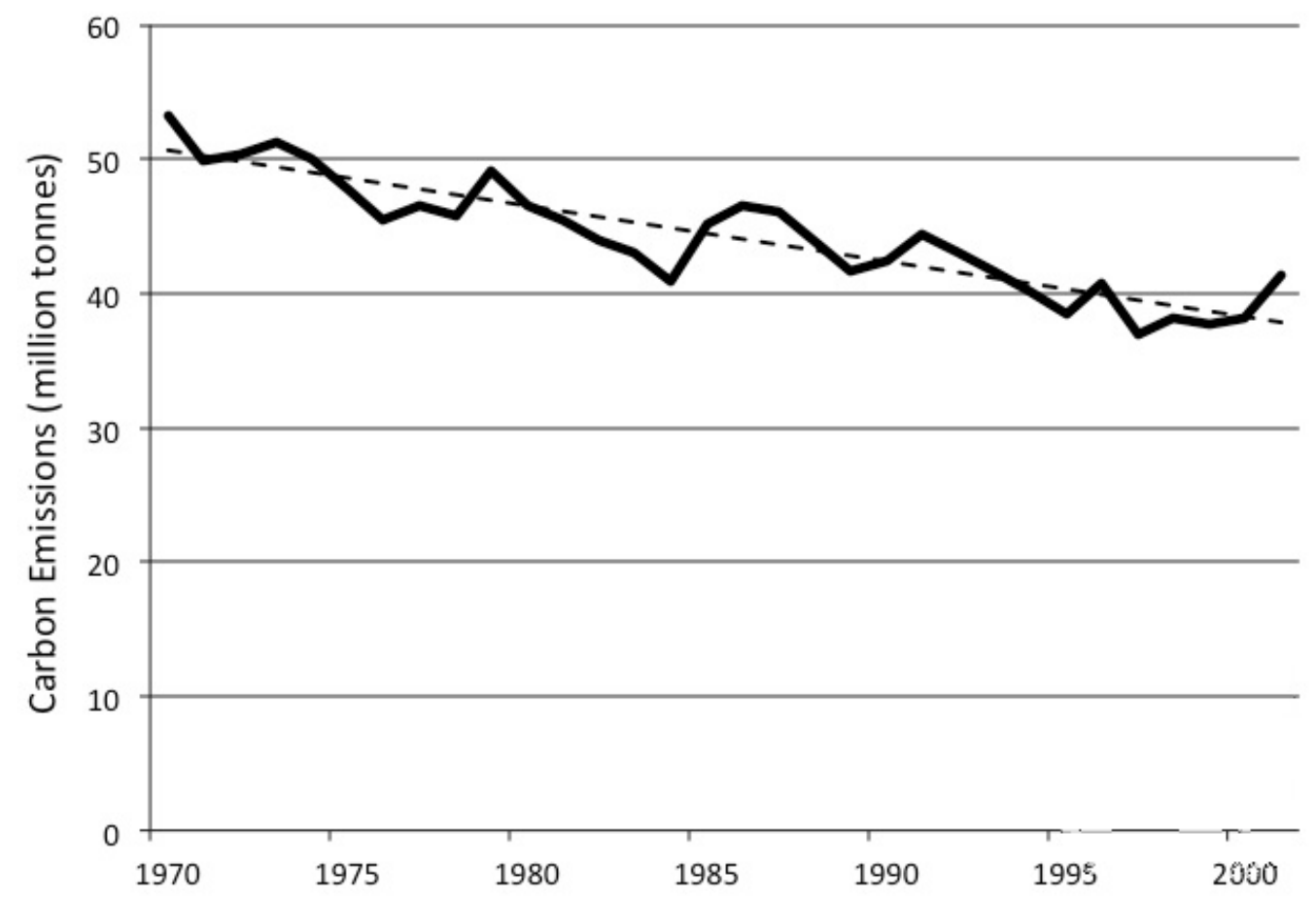

Fig 3 Carbon emissions due to domestic energy consumption, 1970 to 2001 (Source: Shorrock and Utley, 2003)

Table 1 UK policies and programmes for energy efficiency upgrades to existing housing

\begin{tabular}{ll}
\hline Building Regulations & The primary tool for driving energy performance of \\
Part L & new housing. For existing housing, it only applies to \\
& building extensions, windows, conservatories, and \\
& major renovations.
\end{tabular}

Environmental Health Requires that excess cold in houses is avoided to Regulation reduce risks to vulnerable occupants.

Decent Homes

Standard

\section{Scottish Housing Quality Standard}

Warm Front
Requires improvements in substandard social housing through investment in new kitchens, bathrooms, and central heating systems. The standard has provided insulation for more than 600,000 houses and double-glazing for more than 80,000 houses.

Requires that local authorities and registered social landlords ensure that their houses are energy efficient, are equipped with modern facilities and services, and are free from serious disrepair by 2015.

Provides grants of up to $£ 3500$ for energy efficiency improvements to low-income households in England including loft and cavity wall insulation, draughtproofing, and heating system upgrades. To 
date, almost 2.3 million households have participated in the scheme.

\author{
Landlord's Energy \\ Saving Allowance \\ (LESA)
}

\section{Carbon Emissions Reduction Target (CERT)}

\section{The Green Deal}

Feed-in Tariffs (FITs) Scheme

\section{Renewable Heat Incentive (RHI)}

A tax allowance for landlords to offset the cost of buying and installing insulation and draughtproofing for rental properties. Eligible parties can claim up to $£ 1500$ per year per household through the scheme.

A programme that requires all domestic energy suppliers to deliver carbon reductions through wholly or partially subsidised energy-saving measures. Since 2002, CERT has provided subsidies to 7.5 million homes.

The flagship programme of the current Government enables owners and occupants to install energyefficiency measures up to $f 6500$ through a pay-asyou-save finance package (the cost of the energyefficiency measures will be recouped through energy bill savings). The market-driven policy was launched in January 2013 and replaced CERT.

Introduced in April 2010 to encourage the installation of small-scale low-carbon and renewable technologies. Property owners who install on-site technologies such as photovoltaics, wind turbines, and micro combined heat and power systems are eligible to be paid by energy suppliers for energy fed back into the grid.

Provides financial support for households to switch from fossil fuels to renewables. Since August 2011, households have applied for vouchers to offset the capital costs of solar thermal hot water, air source heat pumps, ground source heat pumps, and biomass boilers. The scheme only applies to households that do not use gas as their main heating fuel.

(Sources: DECC, 2011; DECC, 2012; Directgov, 2012; EST, 2012; NRC, 2012)

Table 2 Examples of information resources and demonstration projects on UK domestic retrofit

Centre for Refurbishment Excellence A new education facility funded by www.core-skills.com private industry, Stoke City Council, Stoke College, and the Building Research Establishment to train the 
domestic refurbishment workforce.

The centre will eventually include an exhibition space for displaying building products and hosting events.

National Refurbishment Centre www.rethinkingrefurbishment.com

Low Energy Building Database

\section{Great British Refurb Programme www.greatbritishrefurb.co.uk}

The Green Register www.greenregister.org.uk

The Superhomes Network www.superhomes.org.uk
A joint initiative between the Energy Saving Trust and the BRE Trust to develop an online database of 500 refurbishment exemplars. The database provides the building sector with information on best practices and regulatory frameworks as well as quantitative and qualitative data on real world projects.

A database with case studies of houses that participated in the Technology Strategy Board's Retrofit for the Future programme. Each case study includes technical information, brief descriptions, and photos.

A partnership between the UK Green Building Council, Grand Designs magazine, and World Wildlife Federation that includes refurbishment case studies for homeowners and the building industry.

A cross-sector partnership of experts and practitioners of domestic refurbishment providing reports and guidance to the building sector.

A not-for-profit organisation that provides training to the building industry as well as an accredited directory of building professionals for homeowners.

A database of over 100 exemplar older houses that have achieved at least a $60 \%$ reduction in carbon emissions. The network hosts open days in March and September to provide public tours of some of the houses. The network also provides reviews of consultants, builders, and suppliers, as well as 
courses and advice on refurbishment.

Victorian Terrace Project at BRE

www.bre.co.uk/podpage.jsp?id=2426

Birmingham Zero Carbon House

zerocarbonhousebirmingham.org
BRE's 'flagship refurbishment project'

will act as a laboratory for new products and design strategies for retrofitting existing houses.

A homegrown demonstration project of a 1840 s semi-detached house in Birmingham that has been refurbished by the homeowner to meet Level 6 (Zero Carbon) of the Code for Sustainable Homes.

Table 3 Examples of community-based housing retrofit programmes

Refit West

Retrofit Reality

FutureFit

Sadberge Energy Saving

Project

Transition Streets

Warm Zones

Relish (Residents 4 Low Impact Sustainable Homes)
Forum for the Future and multiple private, public, and charity partners in Bristol

Gentoo Group, Tenant Service Authority, Northumbria University, DECC

Energy Saving Trust, Affinity Sutton, Camco Clean Energy

Sadberge village residents, Energy Saving Trust

South Hams District Council, Beco, Totnes

Town Council, Energy Saving Trust, DARE/Energy Action Devon

National Energy Action, Warm Zones

Worthing Homes and Faithorn Farrell Timms, Rydon Group, University of Brighton

Several UK universities, RCUK, E.ON

(Sources: CALEBRE, 2013; EST, 2013; Gentoo Group, 2013; Refit West, 2013; Ross, 2011; Transition Streets, 2013) 